\title{
Dependency, mood instability, and inconsequence traits for discriminating borderline personality disorder
}

\author{
Traços de dependência, instabilidade de humor e inconsequência para \\ discriminação do transtorno da personalidade borderline
}

\author{
Lucas de Francisco Carvalho, (iD Giselle Pianowski (D)
}

\begin{abstract}
Introduction: Borderline personality disorder (BPD) is one of the most widely studied personality disorders (PDs). It recurrently shows traits of emotional lability, anxiety, separation insecurity, depressiveness, impulsiveness, risk exposure, and hostility, mainly affecting the domains of negative affectivity and antagonism.

Objectives: To investigate the most discriminant dimensions of the Dimensional Clinical Personality Inventory (Inventário Dimensional Clínico da Personalidade 2 [IDCP-2]) to distinguish people diagnosed with BPD from people without this diagnosis. Methods: A total of 305 participants were included in this study: psychiatric outpatients diagnosed with BPD $(n=30)$, psychiatric outpatients diagnosed with other PDs $(n=75)$, and a community sample $(n=200)$. BPD traits were assessed using the dependency, mood instability, and inconsequence dimensions of the IDCP-2.

Results: Analysis of variance (ANOVA) comparisons indicated highest mean measures in the BPD group, and mood instability factors were the most discriminant ones when considering all groups. Applying the multiple regression analysis, we found an adjusted $r^{2}=0.50$, and hopelessness was the most predictive measure $(\beta=0.32 ; t=6.19 ; \mathrm{p}<0.001)$.

Conclusions: We found discriminatory capacity for factors of all dimensions, although at different levels, and more consistent results to discriminate the BPD group from the community sample.
\end{abstract}

Keywords: Personality disorders, personality assessment, validity.

\section{Resumo}

Introdução: O transtorno da personalidade borderline (TPB) tem sido um dos transtornos de personalidade (TPS) mais estudados. O TPB recorrentemente apresenta traços de instabilidade emocional, ansiedade, insegurança de separação, depressividade, impulsividade, exposição ao risco e hostilidade, afetando principalmente os domínios relacionados à afetividade negativa e ao antagonismo.

Objetivos: Investigar as dimensões mais discriminativas do Inventário Dimensional Clínico da Personalidade 2 (IDCP-2) para distinguir pessoas diagnosticadas com TPB de pessoas sem esse diagnóstico.

Métodos: Foram incluídos no estudo 305 participantes: pacientes psiquiátricos com TPB $(n=30)$, pacientes psiquiátricos com outros TPs $(n=75)$ e amostra da população geral $(n=200)$. Os traços de TPB foram avaliados utilizando as dimensões dependência, instabilidade de humor e inconsequência do IDCP-2.

Resultados: As comparações com análise de variância (ANOVA) indicaram que o grupo TPB apresentou as maiores médias, e os fatores da dimensão instabilidade de humor foram os mais discriminativos ao se comparar os três grupos. Usando a análise de regressão múltipla, foi encontrado um $r_{\text {ajustado }}^{2}=0,50$, e o fator desesperança foi o mais preditivo $(\beta=0,32 ; t=6,19 ; p<0,001)$. Conclusões: Foi encontrada capacidade discriminativa para fatores de todas as dimensões, embora em diferentes níveis, e resultados mais consistentes quanto à discriminação foram observados para a distinção entre o grupo com TPB e a população geral.

Descritores: Transtornos da personalidade, avaliação da personalidade, validade. 


\section{Introduction}

Borderline personality disorder (BPD) is one of the most widely studied personality disorders (PDs). Within and outside clinical practice, this diagnosis has received growing visibility, causing notable and expressive harm to patients (and to those around them), who suffer with symptoms such as negative relationships, fear of abandonment, identity problems, intense impulsivity, and anger, combined with a distressing feeling of emptiness and emotional lability, often associated with self-harm and suicidal thoughts and behaviors. ${ }^{1-5}$

The assessment of these behaviors and traits is not simple to operationalize, since it may involve individual particularities and comorbidities, in addition to the recognized limitations related to the diagnostic boundaries and fluctuations of BPD. 1,6,7 In a dimensional perspective, patients with BPD recurrently show traits of emotional lability, anxiety, separation insecurity, depressiveness, impulsiveness, risk exposure, and hostility, mainly affecting the negative affectivity and antagonism domains. ${ }^{1,2,6,8,9}$ Some of these BPD features have been considered as indicators of personality impairment severity. ${ }^{10,11}$

Based on the prominent literature about dimensional models of PDs, the self-report test Dimensional Clinical Personality Inventory (Inventário Dimensional Clínico da Personalidade [IDCP] $)^{12-14}$ has shown accuracy in the evaluation and identification of traits associated with BPD. Although no study has been published testing the accuracy of the revised version of the IDCP (i.e., IDCP-2), ${ }^{15}$ results found with the first version of the IDCP can be generalized to the dimensions of IDCP-2, since the correlation between the total scores of the two versions tends to be around $0.90 .{ }^{16-18}$ The IDCP2 includes 47 factors distributed into 12 dimensions. Several personality dimensions could be acknowledged as pertinent to BPD; however, conceptually and as in line with previous studies, ${ }^{13,14}$ we highlight the dimensions of dependency, mood instability, and inconsequence, since they include factors related to separation insecurity, oscillation and emotional vulnerability, as well as impulsiveness and extreme reactions. ${ }^{16-19}$

The aim of this study was to investigate the most discriminant IDCP-2 dimensions and factors to distinguish people diagnosed with BPD from people without this diagnosis. To that end, we administered three dimensions of the IDCP-2, namely dependency, mood instability, and inconsequence, also considering their individual factors.

\section{Methods}

This was a cross-sectional study conducted in Brazil as part of clinical studies with IDCP-2 (e.g., Carvalho et $\mathrm{al}^{20}$ ).

\section{Sample}

A total of 305 participants were included in this study, divided into three groups: psychiatric outpatients diagnosed with BPD (BPD group; $n=30$ ), aged 1956 years (mean $[\mathrm{M}]=36.7$; standard deviation [SD] $=10.5)$, consisting mainly of women (83.3\%), people with white skin color $(70 \%)$, and undergraduate students (73.4\%); psychiatric outpatients diagnosed with other PDs ( $n=75$; non-BPD group), aged 1973 years $(M=41.8 ; S D=13.1)$, composed mostly of females $(76 \%)$, people with white skin color $(62.7 \%)$, and undergraduate students (72\%); and a community sample $(n=200)$, aged $19-58$ years $(M=24.1 ; S D=$ $5.9)$, and also composed mainly of women (55.5\%), people with white skin color $(77 \%)$, and undergraduate students $(95.5 \%)$.

Patients from the first and second groups were diagnosed by psychiatrists using the Structured Clinical Interview for DSM-IV Axis I Disorders Structured Clinical Interview for DSM-IV Axis II Disorders (SCIDII). Individuals from the community sample reported no history or current psychological and/or psychiatric treatment.

\section{Dimensional Clinical Personality Inventory 2 (IDCP-2)}

The IDCP is a self-report inventory for adults developed in Brazil for the evaluation of PD symptoms for clinical purposes. We used the revised version, IDCP- $2,{ }^{15}$ which covers relevant content such as sections 2 and 3 of the 5 th edition of the Diagnostic and Statistical Manual of Mental Disorders (DSM-5) and Millon's theory. ${ }^{3}$ The IDCP- 2 comprises 206 items rated on a Likert scale ranging from 1 ("it has nothing to do with me") to 4 ("it has a lot to do with me"). The IDCP2 comprises 12 dimensions (divided into 47 factors); however, based on previous studies with the IDCP, 13,14 we selected the dimensions and factors more strongly related to $B P D$, i.e., dependency ${ }^{17}$ (self-devaluation, avoidance of abandonment, and insecurity), mood instability ${ }^{18}$ (vulnerability, anxious worry, and hopelessness), and inconsequence ${ }^{16}$ (impulsiveness, risk taking, and deceitfulness). Validity evidence (based on internal structure and external criteria) and reliability indexes were assessed for these dimensions in previous 
studies, indicating the psychometric adequacy of these dimensions and their respective factors. ${ }^{16-21}$ Previous studies $^{16-21}$ found validity evidence for the IDCP-2, including coherent correlations between its dimensions and factors with the Personality Inventory for DSM-5 (PID-5). For our sample, Cronbach's alphas calculated for the dimensions varied from 0.87 to 0.91 .

\section{Procedure}

The research was approved by the ethics committee of Universidade São Francisco. People from the community sample were recruited via social networks, and the IDCP-2 was administered online. The two outpatient groups were invited to participate through a Brazilian university psychiatry hospital. All participants received detailed information concerning the aims of the study and signed an informed consent prior to data collection and use.

\section{Data analysis}

Some individuals did not answer all IDCP-2 items; therefore, at first we applied an equating procedure 22,23 using a dataset with 7,175 individuals, allowing the computation of all dimensions and factors to the sample. Then, we extracted the individuals labeled as outpatients with PDs $(n=105)$ and randomly selected 200 individuals labeled as community sample. From that, we settled the database composed of 305 individuals.

We analyzed data using repeated measures analysis of variance (ANOVA) and multiple regression analysis. Repeated measures ANOVA was applied to compare the results obtained for the three groups in each IDCP2 domain and factor assessed in this study; multiple regression analysis was conducted to select the most discriminant factors. In the regression analysis, the variable to be predicted was a group variable including the three sample groups used in this study. Predictors were all the IDCP-2 factors previously described. The level of significance was set at $\leq 0.05$. The analyses were conducted using the Statistical Package for the Social Sciences (SPSS) version 21.0.

\section{Results}

Repeated measures ANOVA results are presented in Figure 1, showing significant differences $(p<0.001)$ between groups. The following IDCP-2 dimensions are represented: dependency (upper left), mood instability (upper right), and inconsequence (bottom left). In the bottom right, a graph showing the best predictors is presented and will be discussed further later in this paper.
In relation to the first three charts in Figure 1 , the BPD group showed the highest means in all cases, and the community sample tended to have the lowest means in almost all cases (except for inconsequence factors). Mood instability factors were the most discriminant ones when considering all three groups, even though a clear distinction could be observed for all dimensions.

Next, we applied multiple regression analysis to determine the best predictors of BPD among the three IDCP-2 dimensions. First, we used both total scores $(n=3)$ and factors $(n=9)$, but the multicollinearity test was positive. When using only the nine factors, the multicollinearity test was negative. The $r^{2}$ adjusted was equal to 0.50 , and three factors were significant $(p<0.05)$ : hopelessness $(\beta=0.32 ; t=6.19 ; p<$ $0.001)$, risk taking $(\beta=-0.19 ; \mathrm{t}=-2.33 ; \mathrm{p}=0.02)$, and impulsiveness $(\beta=0.17 ; \mathrm{t}=2.18 ; \mathrm{p}=0.03)$, as well as the demographic control variable age $(\beta=0.44$; $\mathrm{t}=$ 9.566; $\mathrm{p}=\mathrm{p}<0.001$ ). Unexpectedly, risk taking presented a negative weight in the regression analysis. However, since there was a positive correlation between this variable and the other measures and the negative weight persisted even after excluding the control variables, we can assume that the negative weight was due to the other predictors in the model.

Based on the results obtained with multiple regression analysis, repeated measures ANOVA was conducted using the three significant factors and controlling for age and sex. The resulting graph is presented in Figure 1 (bottom right). Hopelessness was the best discriminating factor when considering all groups. Impulsiveness was a good discriminator between the BPD group and the other groups, whereas risk taking was a good discriminator between the BPD and the non-BPD groups. The Tukey post hoc analysis indicated a clear distinction between the BPD group and the community sample, but not between the BPD and the non-BPD groups.

\section{Discussion}

When faced with tools composed of several factors, professionals can choose to administer only the most relevant measures for a given situation. In cases where the professional suspects that the patient has BPD, there are some traits typically related to this PD. ${ }^{1-6}$ In this study, we assessed IDCP-2 measures related to emotional dependency, affective/mood instability, and reckless behavior (inconsequence). ${ }^{15}$ Overall, we found discriminatory capacity for factors from all dimensions, although at different levels, and more consistent results to discriminate patients with BPD from the community 
sample. Corroborating the previous literature, ${ }^{13}$ the BPD group showed the highest scores in all cases. Hopelessness, which is associated with emptiness and suicidality, both typical of BPD, ${ }^{1-6}$ showed the best performance in discriminating the three groups.

Repeated measures ANOVA showed that the BPD group had the highest scores in all cases, whereas the community sample had the lowest means in all cases except for the inconsequence factors. The characteristics of the non-BPD group may help explain this result, since this group was mainly composed of participants with cluster C PDs ( 50\%), in which impulsiveness, risk taking, and deceitfulness are not typical. Future research should replicate this analysis using a more balanced non-BPD sample.

The factors from mood instability (mainly hopelessness and vulnerability) and dependency (mainly avoidance of abandonment) showed the best discriminant power between groups. This is probably due to the convergence between BPD traits and the content of these particular factors, primarily comprising mood instability and emotional dependency from others. ${ }^{1-6}$ The factors belonging to the inconsequence dimension were also discriminant, especially distinguishing the BPD group from the non-BPD group. Although impulsiveness is also a common characteristic of BPD, the inconsequence dimension of the IDCP-2 is perhaps more related to antisocial PD rather than to BPD. ${ }^{15}$ Future studies should compare BPD and antisocial PD regarding the inconsequence dimension of the IDCP- 2 .

In conclusion, it is noteworthy that the mood instability, dependency, and inconsequence dimensions of the IDCP- 2 proved capable of distinguishing the BPD group from the community sample but were not effective
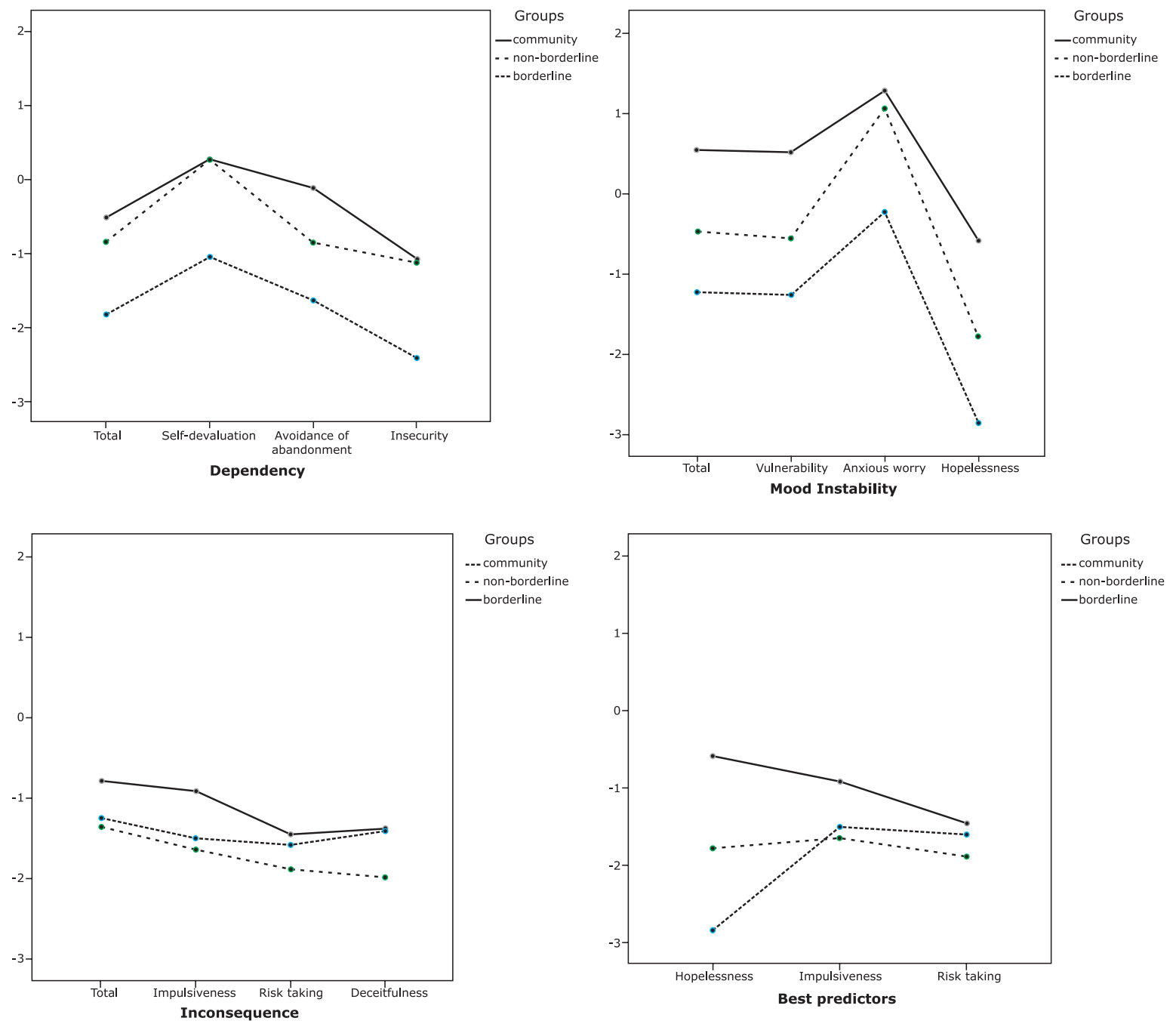

Figure 1 - Repeated measures analysis of variance graphs with Dimensional Clinical Personality Inventory 2 (IDCP-2) dimensions. 
in differentiating the BPD group from the non-BPD group. This result may be related to the fact that BPD traits are a general latent indicator of personality impairment severity, ${ }^{10,11}$ approaching those psychiatric groups on the basis of severity. When considering all three groups, mood instability and dependency showed the best performance. However, when considering the BPD and non-BPD groups only, inconsequence factors showed better discriminating capacity in comparison to the factors belonging to the mood instability and dependency dimensions. Future studies should investigate more deeply the negative weight of the risk taking factor. In all cases, hopelessness was clearly the most discriminative measure. Regarding this factor, it is interesting to note that the BPD and nonBPD groups presented a similar profile, although the BPD group showed the highest mean (Figure 1); however, the community sample showed an expressive decrease for the hopelessness factor in comparison to the other groups (and to the other two factors). Moreover, future studies should try to replicate the present findings using a sample with more BPD cases; measurement invariance should be tested considering the regression model employed; and the same design used with BPD should be applied for other PDs, selecting relevant IDCP-2 factors.

The main limitations of this study were: use of equating, which increased measurement error but at the same allowed to fulfill partially missing cases in the dataset; unbalanced composition of the non-BPD group; absence of diagnostic evaluation of the community sample; and lack of specific knowledge regarding the negative weight presented by the risk taking factor.

\section{Acknowledgements}

This study was supported by grant 2017/03361-5 from Fundação de Amparo à Pesquisa do Estado de São Paulo (FAPESP).

\section{Disclosure}

No conflicts of interest declared concerning the publication of this article.

\section{References}

1. American Psychiatric Association. Diagnostic and Statistical Manual of Mental Disorders, Fifth Edition (DSM-5). Arlington: American Psychiatric Publishing; 2013.

2. Fowler JC, Madan A, Allen JG, Patriquin M, Sharp C, Oldham JM, et al. Clinical utility of the DSM-5 alternative model for borderline personality disorder: Differential diagnostic accuracy of the BFI, SCID-II-PQ, and PID-5. Compr Psychiatry. 2018;80:97-103.
3. Millon $\mathrm{T}$, Millon CM, Meagher SE, Grossman SD, Ramnath R. Personality disorders in modern life. 2nd ed. New Jersey: John Wiley \& Sons; 2004.

4. Paris JA. A concise guide to personality disorders. Washington: American Psychological Association; 2015.

5. Stanley B, New AS. Borderline personality disorder. New York: Oxford University Press; 2018.

6. Kotov R, Krueger RF, Watson D, Achenbach TM, Althoff RR, Bagby RM, et al. The Hierarchical Taxonomy of Psychopathology (HiTOP): A dimensional alternative to traditional nosologies. J Abnorm Psychol. 2017;126:454-77.

7. Skodol AE, Clark LA, Bender DS, Krueger RF, Morey LC, Verheul $\mathrm{R}$, et al. Proposed changes in personality and personality disorder assessment and diagnosis for DSM-5 Part I: Description and rationale. Personal Disord. 2011;2:4-22.

8. Krueger RF, Derringer J, Markon KE, Watson D, Skodol AE. Initial construction of a maladaptive personality trait model and inventory for DSM-5. Psychol Med. 2012;42:1879-90.

9. Samuel DB, Lynam DR, Widiger TA, Ball SA. An expert consensus approach to relating the proposed DSM-5 types and traits. Personal Disord. 2012;3:1-16.

10. Clark LA, Nuzum H, Ro E. Manifestations of personality impairment severity: comorbidity, course/prognosis, psychosocial dysfunction, and "borderline" personality features. Curr Opin Psychol. 2018;21:117-21.

11. Busch AJ, Morey LC, Hopwood CJ. Exploring the assessment of the DSM-5 alternative model for personality disorders with the personality assessment inventory. J Pers Assess. 2017;99:2118.

12. Carvalho LF, Primi R. Development and internal structure investigation of the Dimensional Clinical Personality Inventory. Psicol Reflex Crit. 2015;28:322-30.

13. Abela RK, Carvalho LF, Cho SJM, Yazigi L. Validity evidences for the Dimensional Clinical Personality Inventory in outpatient psychiatric sample. Paideia. 2015;25:221-8.

14. Carvalho LF, Hauck Filho N, Pianowski G, Muner LC. Latent structure of antisocial and borderline personality disorders: a taxometric research. Paideia. 2019;29:e2902. https://dx.doi. org/10.1590/1982-4327e2902

15. Carvalho LF, Primi R. Technical manual of the Dimensional Clinical Personality Inventory 2 (IDCP-2) and Dimensional Clinical Personality Inventory screening version (IDCP-triagem). São Paulo: Pearson; Forthcoming 2019.

16. Carvalho LF. Review study of the Impulsiveness Dimension of the Dimensional Clinical Personality Inventory. Universitas Psychologica. 2018;17:1-11.

17. Carvalho LF, Pianowski G. Revision of the dependency dimension of the Dimensional Clinical Personality Inventory. Paideia. 2015;25:57-65.

18. Carvalho LF, Sette CP. Review and verification of the psychometric properties of the mood instability dimension of the Dimensional Clinical Personality Inventory. Acta Colom Psicol. 2015;18:11527.

19. Carvalho LF, Pianowski G, Hauck Filho N. Establishing a clinically relevant cutoff to the dependency scale from the Dimensional Clinical Personality Inventory. Psychiatry Res. 2017;251:26-33.

20. Carvalho LF, Pianowski G, Gonçalves A. Dimensional Clinical Personality Inventory-2: investigating key factors on the assessment of dependent personality disorder. Psychol Health Med. 2018 Dec 5:1-7. doi: 10.1080/13548506.2018.1554254. [Epub ahead of print]

21. Carvalho LF, Primi R, Stone GE. Psychometric properties of the Inventário Dimensional Clínico da Personalidade (IDCP) using the Rating Scale Model. Av Piscol Clin Latinoam. 2014;32:429-42.

22. Thomas ML. The value of item response theory in clinical assessment: a review. Assessment. 2011;18:291-307.

23. Wyse $A E$, Reckase MD. A graphical approach to evaluating equating using test characteristic curves. Appl Psychol Meas. 2011;35:217-34.

\section{Correspondence:}

Giselle Pianowski

Departamento de Psicologia, Universidade São Francisco Rua Waldemar César da Silveira, 105, VI. Cura D’Ars (SWIFT)

13045-510 - Campinas, SP - Brazil

Tel.: + 55 (11) 45348000

E-mail: gisellepianowski@gmail.com, lucas@labape.com.br 